\title{
Novel methods to study the effect of protein content and dissolution temperature on the solubility of milk protein concentrate: Focused beam reflectance and ultrasonic flaw detector-based methods
}

\author{
M. Hauser and J. K. Amamcharla ${ }^{1}$ \\ Department of Animal Sciences and Industry/Food Science Institute, Kansas State University, Manhattan 66506
}

\begin{abstract}
Processing, storage, dissolution conditions, and the composition of milk protein concentrates (MPC) affect the solubility of high-protein dairy powders. Increasing the storage temperature and time decrease the solubility of MPC and milk protein isolates (MPI). The MPC and MPI are popular ingredients in high-protein food products and have a variety of protein contents. In addition, the dissolution temperature has been shown to affect the solubility of the powders. This study focused on determining how protein content and dissolution temperature affect the solubility of MPC and MPI. For this study, 11 powders were obtained from a commercial manufacturer. The powders were classified as A, $\mathrm{B}, \mathrm{C}$, and $\mathrm{D}$, and they had a mean protein content of $85,87,88$, and $90 \%$, respectively. A $5 \%$ (wt/wt) concentration of powder was dissolved in water at 40 and $48^{\circ} \mathrm{C}$. The solubility of the MPC and MPI samples were characterized using an ultrasonic flaw detector (UFD) and focused beam reflectance measurement (FBRM). The UFD and FBRM data were collected every 15 and $10 \mathrm{~s}$, respectively, for $1,800 \mathrm{~s}$. At both dissolution temperatures, the UFD and FBRM data showed that the solubility decreased as the protein content increased. Powders A and B were found to be more soluble because they had a lower relative velocity standard deviation, high area under the attenuation curve, high peak height, and low peak time. With the FBRM, the fine and medium particle count decreased and large particle count increased as the protein content increased. Powders dissolved at $48^{\circ} \mathrm{C}$ typically had a lower relative velocity standard deviation, higher area under the attenuation curve, higher peak height, and lower peak time than the powders dissolved at $40^{\circ} \mathrm{C}$. The FBRM showed that powders dissolved at $48^{\circ} \mathrm{C}$ reached a stable
\end{abstract}

Received October 19, 2015.

Accepted January 24, 2016.

${ }^{1}$ Corresponding author: Jayendra@ksu.edu counts before the powders dissolved at $40^{\circ} \mathrm{C}$. Overall, the study showed that increasing the protein content led to a reduction in solubility and increasing the dissolution temperature improved the solubility of the powders.

Key words: milk protein concentrate, dissolution behavior, focused beam reflectance measurement, flaw detector

\section{INTRODUCTION}

High-protein dairy powders such as milk protein concentrates (MPC) and milk protein isolates (MPI) are added to a variety of dairy and food products to improve the nutritional, sensory, and functional properties. The protein content of MPC and MPI ranges from 40 to $90 \%$. Generally, powders with a protein content of $80 \%$ or above are added to high-protein nutrition bars, meal replacement beverages, and medical nutrition products (Agarwal et al., 2015). The MPC and MPI must be soluble to give the products the desired characteristics. However, various factors such as processing conditions, composition of the powder, storage conditions, and dissolution conditions affect the overall solubility of MPC and MPI.

Lactose, minerals, and water are removed from skim milk during ultrafiltration and diafiltration to concentrate the proteins in their native form (Chandan and Kilara, 2011). However, subsequent processing steps such as evaporation and spray drying partially denature the protein, which leads to a reduction in solubility of the finished product (Augustin et al., 2012; Fang et al., 2012). Various techniques have been proposed to improve the solubility of high-protein dairy powders. Mao et al. (2012) reported that the MPC80 powder obtained by addition of $150 \mathrm{mM} \mathrm{NaCl}$ during diafiltration showed highest solubility during reconstitution. The addition of a sodium solution to the retentate before spray drying has been shown to improve the solubility (Schuck et al., 2007). In a study conducted by Augustin et al. (2012), the addition of a high shear treatment such as homogenization, microfiltration, and ultrasoni- 
cation improved the solubility of the powder even after 6 mo of storage.

The major and minor components of MPC and MPI such as protein, lactose, and mineral influence the solubility. A reduction in rehydration time was observed for powders with a higher lactose and whey protein concentration (Gaiani et al., 2006, 2007). In a study reported by Sikand et al. (2011), MPC40 samples were appear to be more soluble compared with MPC 80 and MPI samples, with a couple of exceptions. The exceptionally high solubility of MPI samples was attributed to low calcium and phosphorus contents when compared with the other samples tested. The MPC powders have the best solubility immediately after production and the solubility decreases as the storage time and temperature increases. (Anema et al., 2006; Fang et al., 2011; Gazi and Huppertz, 2015).

Studies have shown that increasing the stirring speed and temperature decreased the rehydration time. Jeantet et al. (2010) reported that increasing the dissolution temperature from 26 to $30^{\circ} \mathrm{C}$ was more effective than doubling the stirring speed in increasing the solubility and concluded that temperature has a major effect on rehydration behavior of micellar casein powder. Fang et al. (2011) noticed that a higher dissolution temperature improved the ability to detect solubility differences between fresh and aged powders. However, a dissolution temperature at or above $60^{\circ} \mathrm{C}$ led to a reduction in solubility due to protein denaturation and aggregation (Fang et al., 2010).

Baldwin (2010) highlighted the need for information on instrumental measurements and solubility measurements of powders to probe insolubility phenomenon in milk powder products. Ji et al. (2016) also recognized the need for more reliable techniques tailored for dairy powders and evaluated methods including light scattering, light transmission, and conductivity of suspension, to characterize milk protein-based powders. With this background, still there is a need to quantitatively determine the effect of protein content and dissolution temperature on the dissolution characteristics of highprotein dairy powders. For this study, the objective was to determine the effect of protein content and dissolution temperature on the dissolution characteristics of MPC and MPI as measured by an ultrasonic flaw detector (UFD) and focused beam reflectance measurement (FBRM).

\section{MATERIALS AND METHODS}

\section{Experimental Design}

From a commercial manufacturer within the United States, 11 MPC powder samples were obtained and the dissolution characteristics of powders were evaluated at 40 and $48^{\circ} \mathrm{C}$ using the UFD-based method and FBRM. Based on the protein content, the powders were divided into 4 categories: A, B, C, and D. As per the certificate of analysis provided by the manufacturer, Powders A, $\mathrm{B}, \mathrm{C}$, and $\mathrm{D}$ had a protein content of $85,87,88$, and $90 \%$, respectively. Powders A and B both contained 3 lots and powders $\mathrm{C}$ and $\mathrm{D}$ contained 4 lots and 1 lot, respectively. Each of the samples was analyzed using the UFD-based method and FBRM in triplicate $(\mathrm{n}=$ $3)$.

\section{Experimental Setup}

Experimental setup as described by Hauser and Amamcharla (2016) was used to acquire dissolution characteristics of powders. Briefly, the setup consisted of a UFD (Epoch LTC, Olympus Scientific Solutions, Waltham, MA), connected to an immersion transducer (V303-SU, Olympus Scientific Solutions) in a holder, and a 4-bladed overhead stirrer (Caframo, Georgian Bluffs, Ontario, Canada) that was placed $10 \mathrm{~mm}$ from the bottom of the beaker. The experimental setup was also fitted with a FBRM (Particle Track E25, Mettler Toledo, Columbus, $\mathrm{OH}$ ) probe. A temperature-controlled water bath (Fisher Scientific, Pittsburgh, PA) was used to maintain the powder dissolution temperature at 40 and $48^{\circ} \mathrm{C}$.

$\boldsymbol{U F D}$. A UFD in pulse-echo mode was connected to a $1-\mathrm{MHz}$ immersion transducer. The ultrasound path length was kept constant at $18 \pm 0.5 \mathrm{~mm}$ with a stainless steel holder. A detailed description of the design of the holder was provided in Hauser and Amamcharla (2016).

Deriving Parameters from UFD. The method for exporting the ultrasound data and calculating the ultrasound velocity, relative ultrasound velocity, and ultrasound attenuation can be found in Hauser and Amamcharla (2016). Relative ultrasound velocity and ultrasound attenuation were plotted against powder dissolution time. From these curves, the standard deviation of relative ultrasound velocity from 900 to $1,800 \mathrm{~s}$, ultrasound attenuation peak height (maximum attenuation), attenuation peak time (time to reach maximum attenuation), and area under the attenuation curve were extracted to characterize powder dissolution. The area under the attenuation curve was calculated using the trapezoidal rule (Potter and Goldberg, 1987). The derived ultrasound parameters were used as a tool to understand the effect of protein content on the solubility of MPC and MPI.

$\boldsymbol{F B R}$. A FBRM was also used to monitor and evaluate the dissolution behavior of the powders. The FBRM was installed at an angle of $30^{\circ}$ and $20 \mathrm{~mm}$ from 
the bottom of the beaker. Data from the FBRM were acquired with the icFBRM 4.3 (Mettler Toledo) software program. The powder particles during dissolution were categorized based on their chord lengths. Counts or number of particles were obtained for particles in the following categories: fine $(<10 \mu \mathrm{m})$, medium $(10-50$ $\mu \mathrm{m})$, and large $(50-150 \mu \mathrm{m})$ particles. The change in counts during the dissolution of a MPC sample was used as a tool to characterize the dissolution behavior of powders. This study focused on particles that were less than $150 \mu \mathrm{m}$. The unweighted function was sensitive to changes for the smaller particles and a square weight was sensitive to large particles (Huang et al., 2010). For this experiment, an unweighted function was used to understand the dissolution behavior of MPC and MPI because the powder particle chord length distribution was dominated by smaller particles. To evaluate the solubility of powders, the rate of change in counts and the counts at $0,300,900,1,200,1,500$, and $1,800 \mathrm{~s}$ were examined.

Evaluating the Dissolution Behavior of MPC and MPI. Eleven powder samples were obtained from a commercial manufacturer and classified as powders $\mathrm{A}, \mathrm{B}, \mathrm{C}$, or D based on their protein content. Each powder was characterized in terms of dissolution behavior using the UFD and FBRM. The distance between the ultrasound transducer and the reflector place was measured using the UFD by placing the ultrasound transducer in water at room temperature $\left(25^{\circ} \mathrm{C}\right)$. For all the samples, a $5 \%$ (wt/wt) concentration was used. In a 1-L beaker, distilled water was allowed to reach the dissolution temperature $\left(40\right.$ or $\left.48^{\circ} \mathrm{C}\right)$ as per the experimental design. The overhead stirrer speed was set at $400 \mathrm{rpm}$ and a baseline ultrasound velocity was acquired. Subsequently, the speed of the stirrer was increased to $900 \mathrm{rpm}$ and the powder was added to water within $3 \mathrm{~min}$. After adding all the powder, the stirrer speed was reset to $400 \mathrm{rpm}$ and data from the UFD and FBRM were acquired every 15 and $10 \mathrm{~s}$, respectively, for $1,800 \mathrm{~s}$. All tests were done in duplicate. From the ultrasound data, 4 parameters were extracted from the ultrasound relative velocity and ultrasound attenuation curves as described in Hauser and Amamcharla (2016).

\section{Statistical Analysis}

Changes in the powder dissolution characteristics observed by the UFD-based method and FBRM methods were analyzed using the PROC GLMMIX procedure of SAS (version 9.4, SAS Institute Inc., Cary, NC). The ultrasound parameters were compared for the protein content and at the different dissolution temperatures.

\section{RESULTS AND DISCUSSION}

The MPC and MPI are generally described as having casein and whey proteins in the same proportion that is observed in fluid milk. Milk protein concentrates typically have protein content between 40 and $85 \%$ and MPI have protein content above $85 \%$ (Agarwal et al., 2015). Generally, the name of the powder indicates the protein content of the powder. For example, MPC 80 and MPI90 contain a protein content of 80 and $90 \%$, respectively. The powders used in the present study had a protein content ranging from 85 to $90 \%$.

The composition for the powders A, B, C, and D is provided in Table 1. The average protein content for powders A, B, C, and D was found to be 85.61, $87.23,88.57$, and $90.02 \%$ on dry basis, respectively. The protein content was significantly different $(P<$ 0.05 ) for the powders A, B, C, and D. As the protein content increased from 85.6 to $90 \%$ for powders A to $\mathrm{D}$, the lactose concentration decreased correspondingly. To produce a higher protein in MPC and MPI, lactose and minerals were removed using ultrafiltration and diafiltration (Agarwal et al., 2015). The lactose content was not significantly different for powders A and B $(P$ $>0.05)$ and for powders $\mathrm{C}$ and $\mathrm{D}(P>0.05)$. However, the lactose content was significantly $(P<0.05)$ different for powders $\mathrm{A}$ and $\mathrm{C}$ as well as powders $\mathrm{A}$ and $\mathrm{D}$. On the other hand, fat content was not significantly different for the powders A to D.

\section{Dissolution Behavior of MPC and MPI at $40^{\circ} \mathrm{C}$}

Evaluating the Dissolution Behavior with a UFD. An ultrasonic flaw detector provides a quantitative and economical alternative to characterize the solubility of high-protein dairy powders (Hauser and Amamcharla, 2016). The UFD collected the time-offlight and amplitude data and subsequently was used to calculate the relative ultrasound velocity and ultrasound attenuation. From the relative ultrasound velocity and attenuation data, the relative velocity standard deviation from 900 to $1,800 \mathrm{~s}$, area under the attenuation curve, attenuation peak height, and attenuation peak time during a 30-min dissolution were calculated. As mentioned by Hauser and Amamcharla (2016), a soluble powder had a low relative velocity standard deviation from 900 to $1,800 \mathrm{~s}$, low ultrasound attenuation peak time, high area under the attenuation curve, and high ultrasound attenuation peak height.

Ultrasound Relative Velocity. As soon as the powder was added to the water, the ultrasound signal was not detected. During dissolution of powder, water entered the powder particles and consequently released 
air into the solution. The released air interfered with the ultrasound measurement and caused a drop in the ultrasound signal (Saggin and Coupland, 2002; Yucel and Coupland, 2011; Richard et al., 2012). Coupland (2004) suggested that the presence of air negatively affected the ultrasound signal by scattering the ultrasound wave. The loss in ultrasound signal led to a fluctuation in relative ultrasound velocity as the UFD was searching for the ultrasound signal. Once the signal was detected, the relative ultrasound velocity increased and typically reached a final relative ultrasound velocity of approximately 1.01 (ratio; no units). To quantify the relative ultrasound velocity trend, the relative velocity standard deviation between 900 and $1,800 \mathrm{~s}$ was extracted from the relative ultrasound velocity collected during the dissolution of powder sample for 1,800 s.

In a previous study by Hauser and Amamcharla (2016), it was reported that the relative ultrasound velocity for fresh MPC samples fluctuated only for a short period of time (around $350 \mathrm{~s}$ ) and had a stable relative ultrasound velocity between 900 and 1,800 s. On the other hand, the relative velocity fluctuated for $1,800 \mathrm{~s}$ for the MPC powders stored at $40^{\circ} \mathrm{C}$ for $4 \mathrm{wk}$ and resulted in a high relative ultrasound velocity standard deviation. Table 2 shows the relative ultrasound velocity standard deviation obtained for all of the powder samples in the present study. The average relative ultrasound velocity standard deviation for powders A and $\mathrm{B}$ was 0.0071 and 0.0091 , respectively, and were determined not to be significantly different $(P>0.05)$. Interestingly, powder $\mathrm{D}$ was not significantly different $(P>0.05)$ from powders $\mathrm{A}$ and $\mathrm{B}$ and powder $\mathrm{C}$ was not significantly different $(P>0.05)$ from powder $\mathrm{D}$ when relative ultrasound velocity standard deviation is considered. Figure 1a shows a typical relative ultra- sound velocity trend obtained for powder types A and $\mathrm{B}$ and can be used to explain the differences in relative ultrasound velocity standard deviation. The lower relative ultrasound velocity standard deviation for powders $\mathrm{A}$ and B was caused by the powder's ability to reach a stable relative ultrasound velocity. The relative ultrasound velocity of powder types A and B fluctuated for 280 and $550 \mathrm{~s}$, respectively, and subsequently showed a clear stabilizing trend. The relative ultrasound velocity trend of powder types A and B can be compared with the relative ultrasound velocity profile obtained for fresh powders as reported by Hauser and Amamcharla (2016).

On the other hand, for the powder types C and D with protein content 88 and $90 \%$, the average relative ultrasound velocity standard deviation increased to 0.0625 and 0.0523 , respectively (Table 2 ). The relative ultrasound velocity standard deviation was not found to be significantly different $(P>0.05)$ for the powders $\mathrm{C}$ and $\mathrm{D}$. Figure $1 \mathrm{~b}$ shows a typical relative velocity trend for powders $\mathrm{C}$ and $\mathrm{D}$ obtained during dissolution. As can be observed, the relative ultrasound velocity for powders $\mathrm{C}$ and $\mathrm{D}$ fluctuated for a longer period of time (900 and 1,275 s, respectively) than powders A and B (only 280 and $550 \mathrm{~s}$ ).

As the protein content increased from 85 to $90 \%$, the increase in relative ultrasound velocity standard deviation and ultrasound fluctuation time from powders A to $\mathrm{D}$ can be explained by the composition of the powders. Increasing the protein content from 85 to $90 \%$ led to a reduction in lactose. Lactose has been shown to decrease the powder dissolution time by causing the water enter the core of the powder particle (Richard et al., 2013). Baldwin (2010) reviewed the role of carbohydrates, especially lactose, in maintaining the native

Table 1. Composition of milk protein concentrate powders used in this study

\begin{tabular}{|c|c|c|c|c|c|c|}
\hline \multicolumn{2}{|c|}{ Powder } & \multicolumn{5}{|c|}{ Component (\%) } \\
\hline Lot & Type & Protein/TS & Moisture & Lactose & Fat & Ash \\
\hline 3 & A & 85.68 & 5.06 & 5.02 & 1.14 & 6.69 \\
\hline Mean \pm SD (A) & & $85.61 \pm 0.07^{\mathrm{a}}$ & $5.12 \pm 0.07$ & $5.60 \pm 0.77^{\mathrm{a}}$ & $1.13 \pm 0.06^{\mathrm{a}}$ & $6.67 \pm 0.06^{\mathrm{a}}$ \\
\hline 1 & B & 86.78 & 5.49 & 4.62 & 1.18 & 6.50 \\
\hline Mean \pm SD (B) & & $87.23 \pm 0.40^{\mathrm{b}}$ & $5.32 \pm 0.19$ & $4.89 \pm 0.73^{\mathrm{a}}$ & $1.11 \pm 0.06^{\mathrm{a}}$ & $6.41 \pm 0.13^{\mathrm{a}}$ \\
\hline 1 & $\mathrm{C}$ & 88.42 & 4.95 & 3.20 & 1.06 & 5.89 \\
\hline 2 & $\mathrm{C}$ & 88.45 & 5.04 & 3.10 & 1.11 & 5.84 \\
\hline 3 & $\mathrm{C}$ & 88.45 & 5.31 & 3.26 & 1.02 & 6.06 \\
\hline 4 & $\mathrm{C}$ & 88.97 & 5.40 & 2.22 & 1.19 & 5.99 \\
\hline Mean \pm SD $(C)$ & & $88.57 \pm 0.30^{c}$ & $5.18 \pm 0.19$ & $2.95 \pm 0.56^{\mathrm{b}}$ & $1.10 \pm 0.09^{\mathrm{a}}$ & $5.95 \pm 0.11^{\mathrm{b}}$ \\
\hline 1 & $\mathrm{D}$ & 90.02 & 4.85 & 2.27 & 1.18 & 5.72 \\
\hline
\end{tabular}

\footnotetext{
${ }^{\mathrm{a}, \mathrm{b}}$ Mean values within a column with different superscripts differ $(P<0.05)$.
} 
Table 2. Means and SEM of parameters obtained from ultrasonic flaw detector-based method during dissolution of milk protein concentrate powders at 40 and $48^{\circ} \mathrm{C}$ $\stackrel{\sim}{\tilde{O}}$

\begin{tabular}{|c|c|c|c|c|c|c|c|c|c|}
\hline \multirow{2}{*}{\multicolumn{2}{|c|}{ Powder }} & \multicolumn{8}{|c|}{ Ultrasound parameter } \\
\hline & & \multicolumn{2}{|c|}{$\begin{array}{l}\text { Relative velocity standard } \\
\text { deviation from } 900 \text { to } 1,800 \mathrm{~s}\end{array}$} & \multicolumn{2}{|c|}{$\begin{array}{l}\text { Area under the attenuation } \\
\text { curve }(\mathrm{Np} \cdot \mathrm{s} / \mathrm{mm})\end{array}$} & \multicolumn{2}{|c|}{$\begin{array}{l}\text { Peak height } \\
(\mathrm{Np} / \mathrm{mm})\end{array}$} & \multicolumn{2}{|c|}{ Peak time (s) } \\
\hline Lot & Type & $40^{\circ} \mathrm{C}$ & $48^{\circ} \mathrm{C}$ & $40^{\circ} \mathrm{C}$ & $48^{\circ} \mathrm{C}$ & $40^{\circ} \mathrm{C}$ & $48^{\circ} \mathrm{C}$ & $40^{\circ} \mathrm{C}$ & $48^{\circ} \mathrm{C}$ \\
\hline 1 & A & 0.0100 & 0.0083 & 68.24 & 85.15 & 0.0732 & 0.0698 & $1,117.5$ & 982.5 \\
\hline 2 & A & 0.0017 & 0.0054 & 63.59 & 82.05 & 0.0619 & 0.0683 & 480.0 & 652.5 \\
\hline 3 & A & 0.0097 & 0.0090 & 66.17 & 84.55 & 0.0689 & 0.0727 & 885.0 & $1,320.0$ \\
\hline $\begin{array}{l}\text { Mean } \pm \text { SEM } \\
(\mathrm{A} ; \mathrm{n}=9)\end{array}$ & & $0.0071 \pm 0.008^{\mathrm{a}, \mathrm{x}}$ & $0.0075 \pm 0.004^{\mathrm{a}, \mathrm{x}}$ & $66.00 \pm 3.96^{\mathrm{a}, \mathrm{x}}$ & $83.92 \pm 4.6^{\mathrm{a}, \mathrm{y}}$ & $0.0680 \pm 0.004^{\mathrm{ab}, \mathrm{x}}$ & $0.0703 \pm 0.001^{\mathrm{a}, \mathrm{y}}$ & $827.5 \pm 113^{\mathrm{a}, \mathrm{x}}$ & $985.0 \pm 143^{\mathrm{a}, \mathrm{y}}$ \\
\hline 1 & B & 0.0080 & 0.0075 & 74.70 & 81.03 & 0.0718 & 0.0757 & 855.0 & $1,740.0$ \\
\hline 2 & B & 0.0183 & 0.0068 & 61.12 & 79.10 & 0.0701 & 0.0772 & $1,087.5$ & $1,140.0$ \\
\hline 3 & B & 0.0010 & 0.0061 & 71.52 & 103.81 & 0.0662 & 0.0807 & 555.0 & $1,200.0$ \\
\hline $\begin{array}{l}\text { Mean } \pm \text { SEM } \\
(\mathrm{B} ; \mathrm{n}=9)\end{array}$ & & $0.0091 \pm 0.008^{\mathrm{a}, \mathrm{x}}$ & $0.0068 \pm 0.004^{\mathrm{a}, \mathrm{x}}$ & $69.11 \pm 3.96^{\mathrm{a}, \mathrm{x}}$ & $87.98 \pm 4.6^{\mathrm{a}, \mathrm{y}}$ & $0.0694 \pm 0.004^{\mathrm{b}, \mathrm{x}}$ & $0.0779 \pm 0.001^{\mathrm{b}, \mathrm{y}}$ & $832.5 \pm 113^{\mathrm{a}, \mathrm{x}}$ & $1,360.0 \pm 143^{\mathrm{a}, \mathrm{y}}$ \\
\hline 1 & $\mathrm{C}$ & 0.0320 & 0.0131 & 39.73 & 60.18 & 0.0655 & 0.0661 & $1,627.5$ & $1,020.0$ \\
\hline 2 & $\mathrm{C}$ & 0.0728 & 0.0262 & 15.80 & 48.12 & 0.0458 & 0.0726 & $1,777.5$ & $1,657.5$ \\
\hline 3 & $\mathrm{C}$ & 0.0437 & 0.0155 & 30.02 & 48.77 & 0.0640 & 0.0656 & 1792.5 & $1,515.0$ \\
\hline 4 & C & 0.1015 & 0.0376 & 5.69 & 48.80 & 0.0260 & 0.0676 & 1440.0 & $1,425.0$ \\
\hline $\begin{array}{l}\text { Mean } \pm \mathrm{SEM} \\
\quad(\mathrm{C} ; \mathrm{n}=12)\end{array}$ & & $0.0625 \pm 0.007^{\mathrm{b}, \mathrm{x}}$ & $0.0231 \pm 0.004^{\mathrm{a}, \mathrm{y}}$ & $22.81 \pm 3.43^{\mathrm{b}, \mathrm{x}}$ & $51.47 \pm 4.0^{\mathrm{b}, \mathrm{y}}$ & $0.0503 \pm 0.004^{\mathrm{a}, \mathrm{x}}$ & $0.0680 \pm 0.001^{\mathrm{a}, \mathrm{y}}$ & $1,659.4 \pm 98^{\mathrm{b}, \mathrm{x}}$ & $1,404.4 \pm 123^{\mathrm{a}, \mathrm{y}}$ \\
\hline $\begin{array}{c}1 \\
\text { Mean } \pm \text { SEM } \\
(\mathrm{D} ; \mathrm{n}=3)\end{array}$ & $\mathrm{D}$ & $\begin{array}{c}0.0523 \\
0.0523 \pm 0.01^{\mathrm{ab}, \mathrm{x}}\end{array}$ & $\begin{array}{c}0.0179 \\
0.0179 \pm 0.008^{\mathrm{a}, y}\end{array}$ & $\begin{array}{c}20.99 \\
20.99 \pm 3.67^{\mathrm{b}, \mathrm{x}}\end{array}$ & $\begin{array}{c}51.63 \\
51.63 \pm 8.0^{\mathrm{b}, \mathrm{y}}\end{array}$ & $\begin{array}{c}0.0489 \\
0.0489 \pm 0.008^{\mathrm{a}, \mathrm{x}}\end{array}$ & $\begin{array}{c}0.0688 \\
0.0688 \pm 0.002^{\mathrm{a}, \mathrm{y}}\end{array}$ & $\begin{array}{c}1,777.5 \\
1,777.5 \pm 196^{\mathrm{b}, \mathrm{x}}\end{array}$ & $\begin{array}{c}1,290.0 \\
1,290.0 \pm 247^{\mathrm{a}, \mathrm{y}}\end{array}$ \\
\hline
\end{tabular}
$(\mathrm{D} ; \mathrm{n}=3)$

$\overline{\mathrm{a}, \mathrm{b}}$ Mean values within a column with different superscript differ $(P<0.05)$.

${ }^{\mathrm{x}, \mathrm{y}}$ Mean values for the dissolution temperatures within an ultrasound parameter that have a different letter differ $(P<0.05)$. 

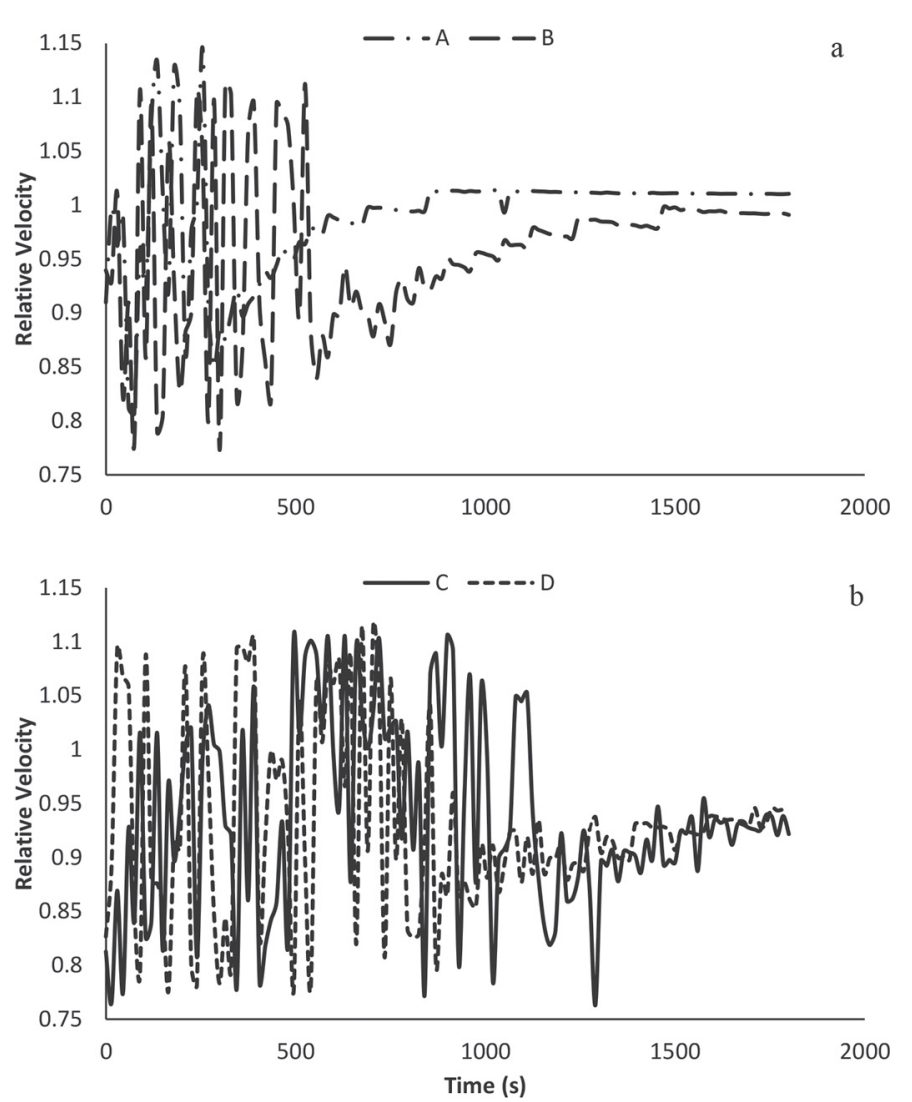

Figure 1. Relative ultrasonic velocity trends obtained from data collected with the ultrasonic flaw detector for powders A and B (a), and $\mathrm{C}$ and $\mathrm{D}(\mathrm{b})$ with a dissolution temperature of $40^{\circ} \mathrm{C}$.

structure protein during drying. The author pointed out that lactose plays an important role in prevention of protein-protein interactions by hydrogen bonding to the protein chain. In addition to lactose, proteinprotein interactions also play a crucial role in deciding solubility characteristics of MPC powders. Havea (2006) stated that the formation of insoluble portion in protein systems such as MPC involved covalent and noncovalent bonds and reported that noncovalent interactions such as hydrophobic, hydrogen bonding, ionic, and other weak interactions were predominantly responsible for formation of insoluble material and consequently contribute to lowering solubility. Mao et al. (2012) found that addition of $150 \mathrm{mM} \mathrm{NaCl}$ during diafiltration resulted in MPC with improved solubility characteristics by modifying the strength of hydrophobic interactions and sulfhydryl-disulfide interactions. With less lactose and more protein in powders $\mathrm{C}$ and D, the water penetrated the powder particle and released air into the solution for a substantially longer period of time. Therefore, the ultrasound signal was lost for a longer period of time, which in turn, increased the rela- tive ultrasound velocity standard deviation. Based on the observations from the relative ultrasound velocity data, we can observe that powder A was more soluble than powder B followed by powders C and D.

Ultrasound Attenuation. In addition to the ultrasound relative velocity, ultrasound attenuation also provided a great deal of information about the dissolution characteristics of MPC. The ultrasound attenuation was more sensitive to particle size distribution in a solution and therefore caused an increase in ultrasound attenuation as the powder particles disintegrate in to solution. To quantify the ultrasound attenuation curve during dissolution of MPC, peak height, peak time, and area under the attenuation curve were extracted from the ultrasound attenuation data. Table 2 shows the peak height, peak time, and area under the attenuation curve for all the powder types A to D.

Figure 2 shows the ultrasound attenuation curve obtained for the powders during dissolution. As can be observed, the ultrasound attenuation of powder types $\mathrm{A}$ and $\mathrm{B}$ increased during the initial dissolution time $(\sim 500 \mathrm{~s})$ and reached a peak. The average ultrasound attenuation peak height for powders $\mathrm{A}$ and $\mathrm{B}$ was found to be 0.068 and $0.069 \mathrm{~Np} / \mathrm{mm}$ and the average peak time was found to be 827 and 832 s, respectively. The peak height and peak time for powders A and B were not significantly different $(P>0.05)$. Similar to ultrasound relative velocity, powder D was not significantly different $(P>0.05)$ from powder A when only ultrasonic peak height is considered. However, the attenuation curve obtained for powder types C and D developed a lag time before the attenuation started to increased. According to Mimouni et al. (2009), MPC powder dissolution involves 2 phenomena occurring simultaneously. Initially, large powder agglomerates are disrupted into primary powder particles and simultaneously, a slow release of material from the primary powder particle into surrounding water phase. The observed lag time in the ultrasonic attenuation curve for powders $\mathrm{C}$ and $\mathrm{D}$ can be attributed to a slow disintegration of agglomerates in the initial phase. The change in the attenuation curve obtained for powder types $\mathrm{C}$ and $\mathrm{D}$ resulted in the average peak height to decrease to approximately 0.05 and $0.049 \mathrm{~Np} / \mathrm{mm}$, respectively, and the average peak time increased to 1,659 and 1,777 s for powders $\mathrm{C}$ and $\mathrm{D}$, respectively. Meyer et al. (2006) demonstrated that the ultrasonic attenuation during dissolution of instant milk powder was affected by particle size and concentration of powder particles and the same particle size distribution also affects the powder reconstitution properties. Consequently, the measurement of ultrasonic attenuation correlated well with the reconstitution quality of instant milk powder. 


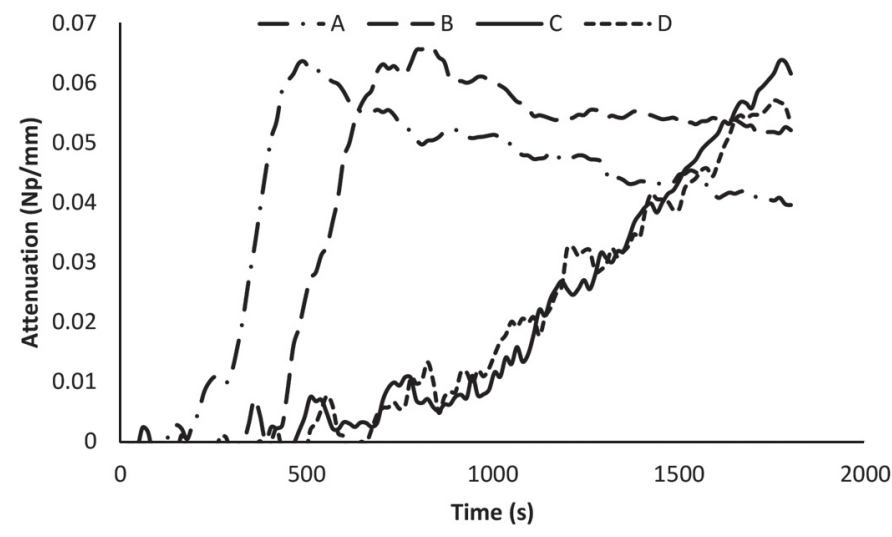

Figure 2. Ultrasonic attenuation trend obtained from the data collected with the ultrasonic flaw detector for powders A, B, C, and D with a dissolution temperature of $40^{\circ} \mathrm{C}$.

Similarly, in the present study, ultrasonic attenuation captured the changes in dissolution characteristics of powder with different protein contents.

A significant difference was not observed $(P>0.05)$ between powders $\mathrm{C}$ and $\mathrm{D}$ for the peak height and peak time. The reduction in peak height and increase in peak time indicated that the solubility decreased as the protein content increased. With the peak height, a significant difference was not noticed $(P>0.05)$ between powders $\mathrm{A}$ and $\mathrm{C}$ and powders $\mathrm{A}$ and $\mathrm{D}$, but a significant different was observed $(P<0.05)$ between powders $\mathrm{B}$ and $\mathrm{C}$. For the peak time, a significant difference was observed $(P<0.05)$ between powders $\mathrm{A}$ and $\mathrm{C}$ as well as D and powders B and C, as well as D. An increase in peak time indicated that the solubility decreased as the protein content increased for the powder types A to D. In a similar study, the ultrasound attenuation peak time increased as the MPC80 was stored for more than a week at $40^{\circ} \mathrm{C}$ (Hauser and Amamcharla, 2016).

To better quantify the changes in the attenuation curve, the area under the attenuation curve was also calculated. The average area under the attenuation curve for powder types A and B was 66 and $69 \mathrm{~Np} \cdot \mathrm{s} /$ $\mathrm{mm}$, respectively. A significant difference $(P<0.05)$ was not observed between powders $\mathrm{A}$ and $\mathrm{B}$. The area decreased by approximately $70 \%$ as the protein content increased from 85 to $90 \%$. For powders $\mathrm{C}$ and $\mathrm{D}$, the average area under the attenuation curve was 22.8 and $21 \mathrm{~Np} \cdot \mathrm{s} / \mathrm{mm}$, respectively. After examining all the ultrasound parameters, we can conclude that powders $\mathrm{A}$ and $\mathrm{B}$ were more soluble than powders $\mathrm{C}$ and D. Significant differences were noticed $(P<0.05)$ between powders $\mathrm{A}$ and $\mathrm{C}$, as well as powders $\mathrm{A}$ and D. Therefore, the UFD showed that an increase in protein content reduced the solubility.
Monitoring the Dissolution Behavior Using $\boldsymbol{F} \boldsymbol{B} \boldsymbol{R} \boldsymbol{M}$. As soon as the powders were added to water, the counts of large particles $(50-150 \mu \mathrm{m})$ decreased as they disintegrated into fine and medium particles. Consequently, the counts of fine $(<10 \mu \mathrm{m})$ and medium particles $(10-50 \mu \mathrm{m})$ started to increase. To determine the solubility using the FBRM-based method, Fang et al. (2011) compared the dissolution rate constant and the final particle size for fresh and aged MPC. Fresh MPC was the most soluble and had a high dissolution rate constant and lower final mean particle size. A similar method was used to understand the dissolution behavior MPC and MPI in the present study.

Figure 3a shows the change in counts for large particles $(50-150 \mu \mathrm{m})$. As can be observed, the large particle counts for powder types $\mathrm{A}$ and $\mathrm{B}$ decreased rapidly, whereas the large particle counts for powders C and D had a gradual reduction. McKenna (2000) reported that casein micelles appeared as individual units during dissolution of MPC56 at $45^{\circ} \mathrm{C}$ for $30 \mathrm{~min}$. As the protein content increased in MPC from 56 to $92 \%$, the MPC92 showed more primary particle aggregates and also exhibited more resistance to dispersing in water. Similarly in this study, a slow reduction in large particle counts $(50-150 \mu \mathrm{m})$ for powders $\mathrm{C}$ and $\mathrm{D}$ shows that as the protein content increases, the time required for the primary particles to disintegrate increased. A similar conclusion was also derived from the ultrasonic attenuation trends. Throughout the experiment, powders $\mathrm{A}$ and $\mathrm{B}$ had lower large particle counts than powders $\mathrm{C}$ and $\mathrm{D}$. At $0 \mathrm{~s}$, powders $\mathrm{A}$ and B had a large particle counts around 2,300 and 4,200, respectively. On the other hand, powders $\mathrm{C}$ and $\mathrm{D}$ had a large particle counts around 6,000. The difference in large particle counts increased at $300 \mathrm{~s}$. Powders A and B had an average large particle count of 490 and 710 , respectively, and the large particle counts for powders $\mathrm{C}$ and D were 7 times higher with large particle counts of 2,500 and 2,300, respectively. By 1,800 s, powders $\mathrm{A}$ and $\mathrm{B}$ had a large particle counts between 70 and 75. Powder A reached the lowest large particle count around 1,200 s and powder B reached the lowest large particle count around 1,500 s. On the other hand, for powders $\mathrm{C}$ and $\mathrm{D}$ (88 and $90 \%$ protein content, respectively), the counts for large particles at 1,800 s were found to be 610 and 450, respectively.

As the large particles disintegrated into smaller particles during dissolution, the counts for medium (Figure $3 \mathrm{~b}$ ) and fine (Figure 3c) particles started to increase. Powders A and B had a medium particle count of 12,500 and 12,100 , respectively, at $0 \mathrm{~s}$. The medium particle count at $0 \mathrm{~s}$ increased as the protein content increased from to 88 and $90 \%$, with powders $\mathrm{C}$ and 
D had a count of 17,000 and 18,000 , respectively. By $900 \mathrm{~s}$, all the powders had a medium particle count of approximately 36,000 and maintained the count for the remainder of the experiment. The fine particles had a similar increasing trend. At $0 \mathrm{~s}$, powders $\mathrm{A}$ and $\mathrm{B}$ had a fine particle count of 12,000 and 13,000 , respectively. Powders A and B were able to reach a fine particle count of 62,000 by $900 \mathrm{~s}$ and maintained this count for the remainder of the experiment. When the protein content increased from 85 to $88 \%$ and $90 \%$, the fine particle counts increased at a slower rate than the powders A and B. Overall, the findings obtained
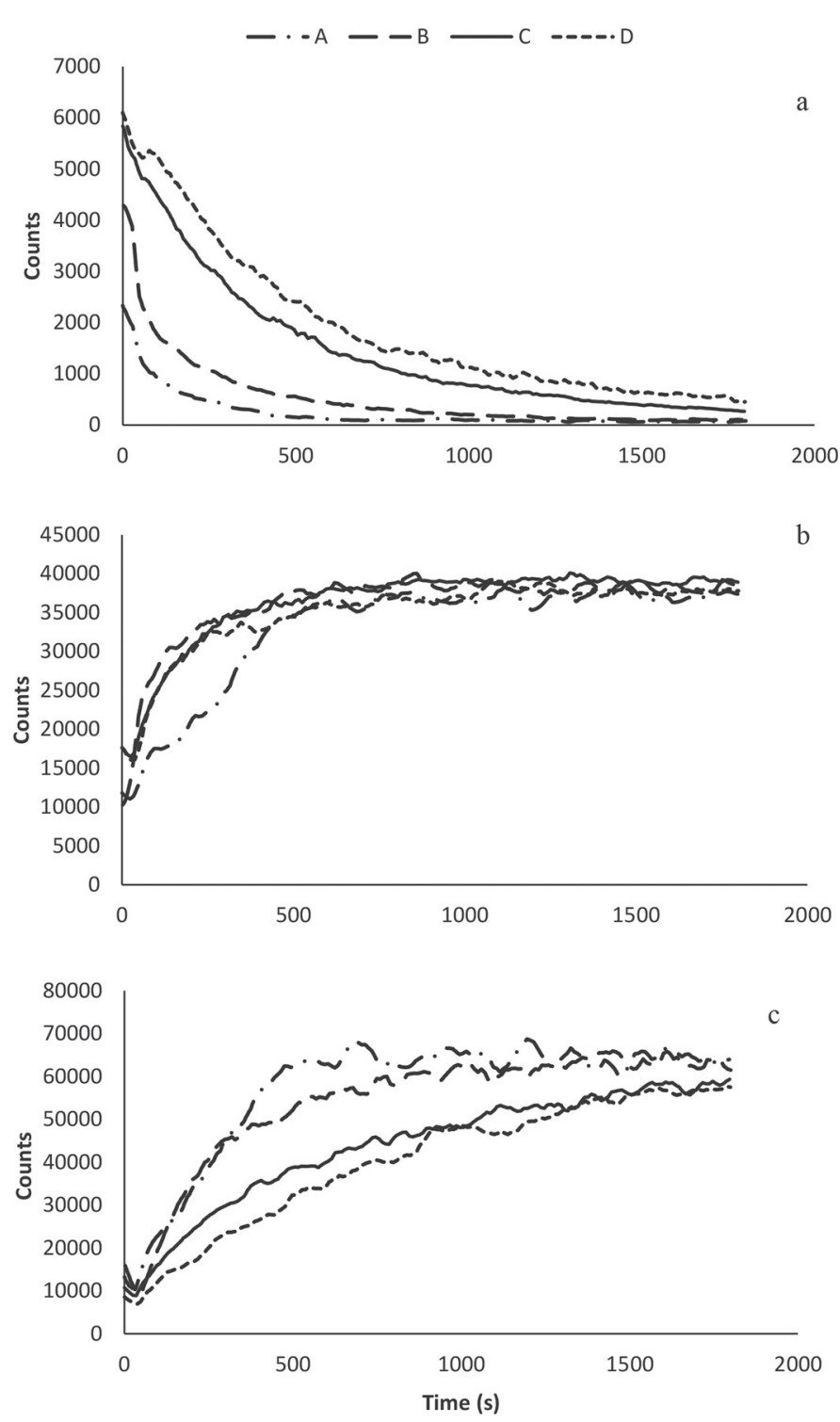

Figure 3. Changes in large (a), medium (b), and fine (c) counts obtained from data collected with the focused beam reflectance measurement for powders $\mathrm{A}, \mathrm{B}, \mathrm{C}$, and $\mathrm{D}$ with a dissolution temperature of $40^{\circ} \mathrm{C}$. from UFD-based method are further supported by the FBRM-based method.

A decreasing final count for fine and medium particles and an increasing count for large particles indicated a reduction in solubility. Powders A and B had higher counts of fine and medium particles, which indicated they were more soluble than powders $\mathrm{C}$ and $\mathrm{D}$, which had a lower count for fine and medium particles. Overall, the FBRM showed that an increase in protein content negatively affected the solubility.

Interpretation of UFD and FBRM data match those of Crowley et al. (2015). The MPC powders with increasing protein content $(35-86 \%)$ were examined for their degree of sediment. A new analytical centrifuge with NIR light intensity measurement capability as a function of time and position was used and the sediment was related to the solubility. Powders with higher protein content had a higher sediment height, which indicated that the powder was less soluble. We found that a reduction in relative velocity standard deviation, increased area under the attenuation, reduction in fine and medium particle counts at 1,800 s, and an increase in large particle counts at 1,800 s indicated the powders with a lower protein content were more soluble.

\section{Dissolution Behavior of MPC and MPI at $48^{\circ} \mathrm{C}$}

Evaluating the Dissolution Behavior with a UFD. The powders dissolved at $48^{\circ} \mathrm{C}$ had a similar relative velocity trend as the powders dissolved at $40^{\circ} \mathrm{C}$. Following the ultrasound relative velocity and attenuation, we observed that the solubility decreased as the protein content increased from $85 \%$ (powder A) to $90 \%$ (powder D). A significant difference $(P<0.05)$ for the relative velocity standard deviation at 40 and $48^{\circ} \mathrm{C}$ was only observed for powders $\mathrm{C}$ and $\mathrm{D}$. The reconstitution conditions such as temperature and type of agitation influence the powder dissolution process. A large acceleration in rehydration of MPC85 was reported by Mimouni et al. (2009) when the rehydration temperature increased from 24 to $35^{\circ} \mathrm{C}$. Table 2 contains the relative velocity standard deviation for all the powders when they were dissolved at $48^{\circ} \mathrm{C}$. Figure $4 \mathrm{a}$ shows the relative ultrasound velocity trend for powders A and B. As the temperature of the water increased, the surface tension of the water decreased. When dissolving a powder, the wettability is the powder particle overcoming the surface tension of water. With a lower surface tension, the water entered the powder particle faster, which led to more air being released into the system. This in turn led to a shorter fluctuation time.

A similar change in relative ultrasound velocity led to a reduction in the relative ultrasound velocity trend for powders $\mathrm{C}$ and $\mathrm{D}$ when they were dissolved at $48^{\circ} \mathrm{C}$. 

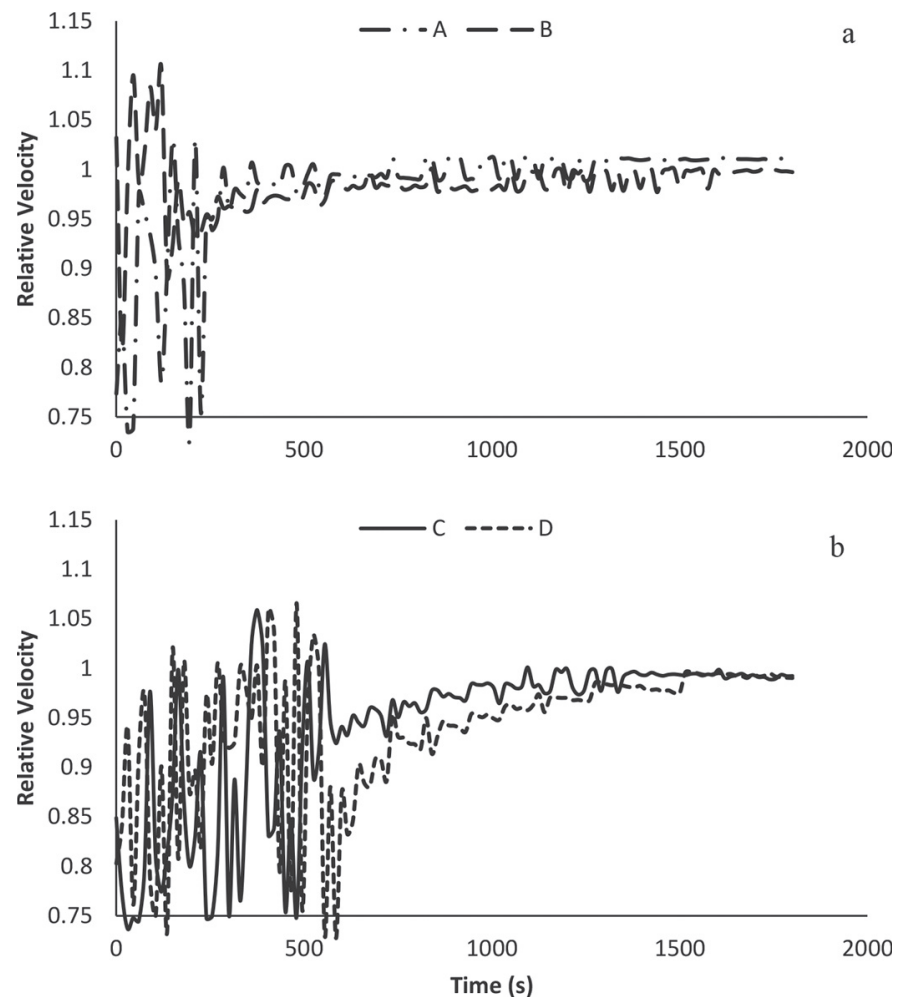

Figure 4. Relative ultrasonic velocity trend obtained from data collected from the ultrasonic flaw detector for powders A and B (a) and powders $\mathrm{C}$ and $\mathrm{D}(\mathrm{b})$ with a dissolution temperature of $48^{\circ} \mathrm{C}$.

Figure $4 \mathrm{~b}$ contains the relative ultrasound velocity trend for powders $\mathrm{C}$ and $\mathrm{D}$. When powders $\mathrm{C}$ and $\mathrm{D}$ were dissolved at $48^{\circ} \mathrm{C}$, the fluctuation time decreased to $500 \mathrm{~s}$ and the relative velocity was able to reach a constant value of 1 .

Figure 5 shows the attenuation curve for all the powders when they were dissolved at $48^{\circ} \mathrm{C}$. All the powders had a trend of an increasing attenuation, reaching a peak, and then stayed relatively constant for the rest of the experiment. Powders C and D had a lag time before the attenuation started to increase. A lag time of 300 and $460 \mathrm{~s}$ was observed for powders $\mathrm{C}$ and $\mathrm{D}$, respectively, during dissolution at $48^{\circ} \mathrm{C}$. However, the lag time for powders $\mathrm{C}$ and $\mathrm{D}$ was approximately 600 s during dissolution at $40^{\circ} \mathrm{C}$. Table 2 contains the extracted ultrasound attenuation parameters. The peak height increased for all the powders when the dissolution temperature increased from 40 to $48^{\circ} \mathrm{C}$. Powders $\mathrm{A}, \mathrm{B}, \mathrm{C}$, and $\mathrm{D}$ had an average peak height of 0.070 , $0.078,0.068$, and $0.069 \mathrm{~Np} / \mathrm{mm}$, respectively. However, the peak time increased for powders $\mathrm{A}$ and $\mathrm{B}$ and decreased for powders $\mathrm{C}$ and $\mathrm{D}$. When examining the area under the attenuation curve, the area increased by 27 , 27, 125, and $145 \%$, respectively, for powders A, B, C, and $\mathrm{D}$. The increased area can be attributed to a faster dissolution rate due to the higher dissolution temperature. A significant difference was observed $(P<0.05)$ between the 40 and $48^{\circ} \mathrm{C}$ dissolution temperature for all the powders. Overall, we observed that the solubility of MPC powders improved with the increased dissolution temperature because a reduction in relative velocity standard deviation and an increase in area under the attenuation curve were observed.

Monitoring the Dissolution Behavior with $\boldsymbol{F B R}$. The FBRM data were also collected when the powders were dissolved at $48^{\circ} \mathrm{C}$. The trends for the large, medium, and fine particles were found to be similar as the trends observed when the powder was dissolved at $40^{\circ} \mathrm{C}$. Using the same analysis technique, the FBRM data showed that powders $\mathrm{A}$ and $\mathrm{B}$ were more soluble than powders $\mathrm{C}$ and $\mathrm{D}$. To determine how the dissolution temperature affected the solubility of the powders, the mean particle size was examined, as well as the time needed to reach the minimum particle size. As can be observed in Figures 6 a and 6 b, powders $\mathrm{A}$ and $\mathrm{B}$ were able to quickly reach the minimum mean particle size when the powders were dissolved at $48^{\circ} \mathrm{C}$. In Figure 6c, it can be observed that the mean particle size of powder $\mathrm{C}$ decreased at a slower rate as compared with powders $\mathrm{A}$ and $\mathrm{B}$, which had a quicker reduction in mean particle size. For powder $\mathrm{C}$, the dissolution temperature of $48^{\circ} \mathrm{C}$ was able to reach the minimum particle size before the dissolution temperature of $40^{\circ} \mathrm{C}$. Figure $6 \mathrm{~d}$ contains the change in mean particle size for powder D. A dissolution temperature of $48^{\circ} \mathrm{C}$ had a similar trend as the $40^{\circ} \mathrm{C}$ dissolution temperature. When dissolved at $48^{\circ} \mathrm{C}$, the minimum particle size was reached around $1,200 \mathrm{~s}$, and when dissolved at $40^{\circ} \mathrm{C}$, the minimum particle size was reached around 1,490 s. As can be observed in all the figures (Figures 6a to

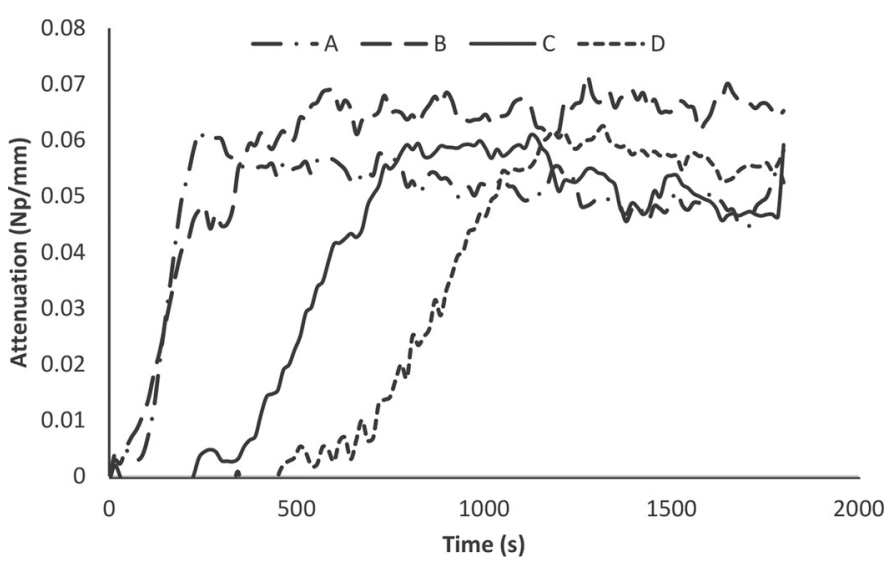

Figure 5. Ultrasonic attenuation trends obtained from the ultrasonic flaw detector for powders A, B, C, and D with a dissolution temperature of $48^{\circ} \mathrm{C}$. 

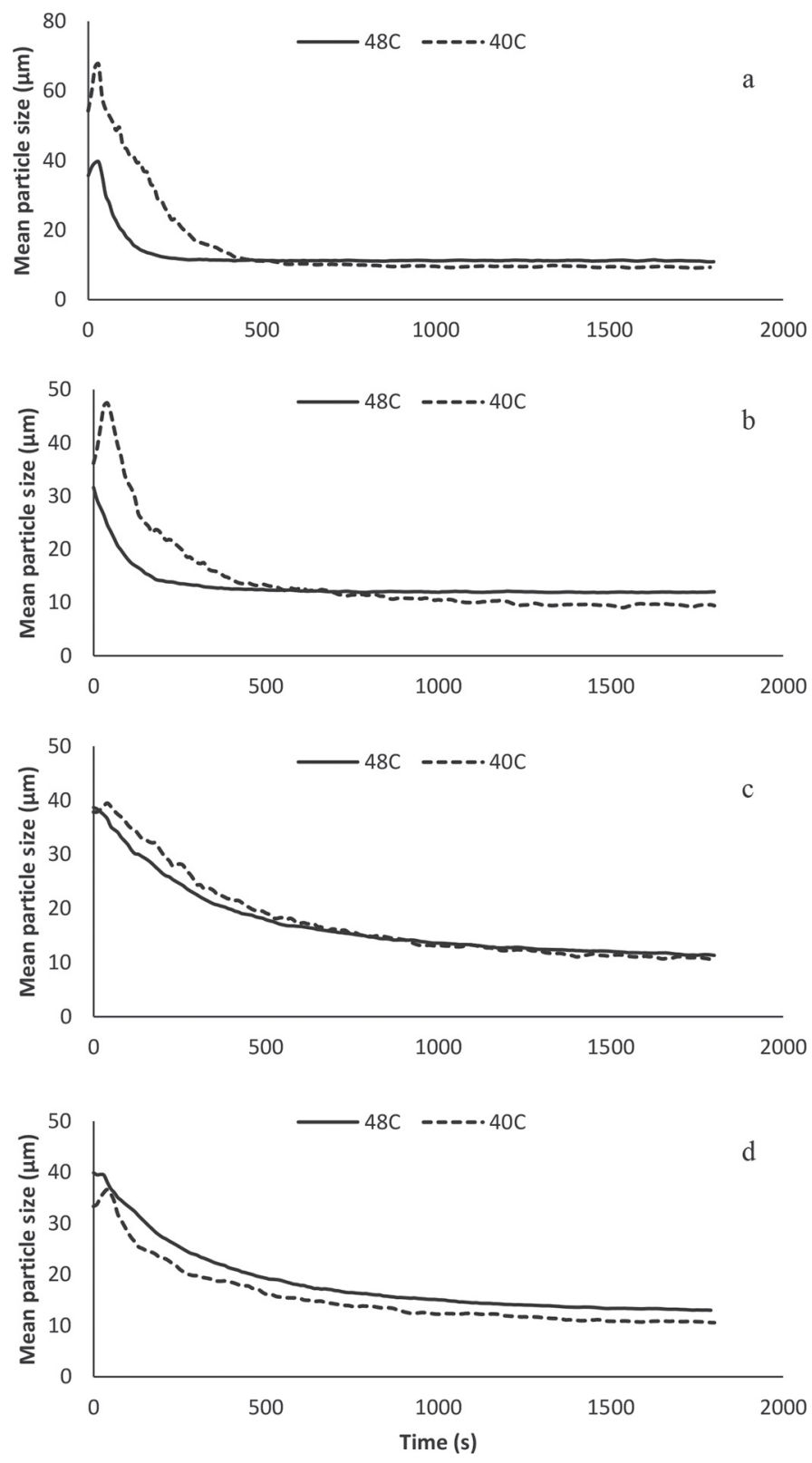

Figure 6. Change in mean particle size $(\mu \mathrm{m})$ obtained from the focused beam reflectance measurement for powders A (a), B (b), C (c), and D (d) with a dissolution temperature of 40 and $48^{\circ} \mathrm{C}$.

6d), the powders dissolved at $40^{\circ} \mathrm{C}$ had a lower mean particle size at a given time during dissolution.

Overall, the FBRM data showed that the MPC powders with a lower protein content such as powder A were more soluble than powders with a higher protein content such as powder $\mathrm{D}$, and that increasing the dissolution temperature from $40^{\circ} \mathrm{C}$ to $48^{\circ} \mathrm{C}$ improved the solubility of the powders. These findings are in agreement with those of Fang et al. (2010) and Jeantet et al. (2010). The authors found that the dissolution time decreased with an increase in dissolution temperature. Fang et al. (2010) attributed the decreased dissolution time to the powder's ability to readily de-agglomerate. A dissolution temperature of $50^{\circ} \mathrm{C}$ typically allowed for the best solubility of MPC and showed more solubility differences for fresh and aged powders (Fang et al., 2010).

\section{CONCLUSIONS}

The UFD and FBRM data showed that the protein content influenced the solubility of the powder at a dissolution temperature of $40^{\circ} \mathrm{C}$ and $48^{\circ} \mathrm{C}$. Increasing the protein content from $85 \%$ to $90 \%$ led to an increase in relative velocity standard deviation and a reduction in the area under the attenuation curve, which indicated an overall reduction in solubility. From the FBRM, a reduction in fine and medium particles and an increase in large particles indicated that the solubility decreased as the protein increased from 85 to $90 \%$. Both the UFD and FBRM showed that the solubility improved when the dissolution temperature increased from 40 and $48^{\circ} \mathrm{C}$. The relative velocity standard deviation decreased and the area under the attenuation curve increased as the dissolution temperature increased. The FBRM showed that the powders dissolved at $48^{\circ} \mathrm{C}$ had a quicker reduction in mean particle size as compared with the powders dissolved at $40^{\circ} \mathrm{C}$, which had a slower change in mean particle size. Overall, we concluded that an increase in protein content and reduction in lactose led to a less soluble powder, and increasing the dissolution temperature improved the solubility of the powders.

\section{ACKNOWLEDGMENTS}

We thank Midwest Dairy Foods Research Center (St. Paul, MN) for their financial support. This is Kansas State Research and Extension contribution number 16126-J.

\section{REFERENCES}

Agarwal, S., R. L. W. Beausire, S. Patel, and H. Patel. 2015. Innovative uses of milk protein concentrates in product development. J. Food Sci. 80:A23-A29.

Anema, S. G., D. N. Pinder, R. J. Hunter, and Y. Hemar. 2006. Effects of storage temperature on the solubility of milk protein concentrate (MPC85). Food Hydrocoll. 20:386-393.

Augustin, M. A., P. Sanguansri, R. Williams and H. Andrews. 2012. High shear treatment of concentrates and drying conditions influence the solubility of milk protein concentrate powders. 79:459 468.

Baldwin, A. J. 2010. Insolubility of milk powder products-A mini review. Dairy Sci. Technol. 90:169-179.

Chandan, R. C., and A. Kilara. 2011. Dairy Ingredients for Food Processing. Wiley-Blackwell, Ames, Iowa.

Coupland, J. N. 2004. Low intensity ultrasound. Food Res. Int. $37: 537-543$. 
Crowley, S. V., B. Desautel, I. Gazi, A. L. Kelly, T. Huppertz, and J. A. O'mahony. 2015. Rehydration characteristics of milk protein concentrate powders. J. Food Eng. 149:105-113.

Fang, Y., S. Rogers, C. Selomulya, and X. Chen. 2012. Functionality of milk protein concentrate: Effect of spray drying temperature. Biochem. Eng. J. 62:101-105.

Fang, Y., C. Selomulya, S. Ainsworth, M. Palmer, and X. D. Chen. 2011. On quantifying the dissolution behaviour of milk protein concentrate. Food Hydrocoll. 25:503-510.

Fang, Y., C. Selomulya, and X. Chen. 2010. Characterization of milk protein concentrate solubility using focused beam reflectance measurement. Dairy Sci. Technol. 90:253-270.

Gaiani, C., J. J. Ehrhardt, J. Scher, J. Hardy, S. Desobry, and S. Banon. 2006. Surface composition of dairy powders observed by $\mathrm{X}$-ray photoelectron spectroscopy and effects on their rehydration properties. Colloids Surf. B Biointerfaces 49:71-78.

Gaiani, C., P. Schuck, J. Scher, S. Desobry, and S. Banon. 2007. Dairy powder rehydration: Influence of protein state, incorporation mode, and agglomeration. J. Dairy Sci. 90:570-581.

Gazi, I., and T. Huppertz. 2015. Influence of protein content and storage conditions on the solubility of caseins and whey proteins in milk protein concentrates. Int. Dairy J. 46:22-30.

Hauser, M., and J. K. Amamcharla. 2016. Development of a method to characterize high-protein dairy powders using an ultrasonic flaw detector. J. Dairy Sci. 99:1056-1064.

Havea, P. 2006. Protein interactions in milk protein concentrate powders. Int. Dairy J. 16:415-422.

Huang, J., G. Kaul, J. Utz, P. Hernandez, V. Wong, D. Bradley, A. Nagi, and D. O' Grady. 2010. A PAT approach to improve process understanding of high shear wet granulation through in-line particle measurement using FBRM C35. J. Pharm. Sci. 99:3205-3212.

Jeantet, R., P. Schuck, T. Six, C. Andre, and G. Delaplace. 2010. The influence of stirring speed, temperature and solid concentration on the rehydration time of micellar casein powder. Dairy Sci. Technol. 90:225-236.

Ji, J., J. Fitzpatrick, K. Cronin, A. Crean, and S. Miao. 2016. Assessment of measurement characteristics for rehydration of milk protein based powders. Food Hydrocoll. A 54:151-161.
Mao, X. Y., P. S. Tong, S. Gualco, and S. Vink. 2012. Effect of NaCl addition during diafiltration on the solubility, hydrophobicity, and disulfide bonds of $80 \%$ milk protein concentrate powder. J. Dairy Sci. 95:3481-3488.

McKenna, A. B. 2000. Effect of processing and storage on the reconstitution properties of whole milk and ultrafiltered skim milk powders. PhD Thesis. Massey Univ., Palmerston North, New Zealand.

Meyer, S., V. S. Rajendram, and M. J. W. Povey. 2006. Characterization of reconstituted milk powder by ultrasound spectroscopy. J. Food Qual. 29:405-418.

Mimouni, A., H. C. Deeth, A. K. Whittaker, M. J. Gidley, and B. R. Bhandari. 2009. Rehydration process of milk protein concentrate powder monitored by static light scattering. Food Hydrocoll. 23:1958-1965.

Potter, M. C., and J. Goldberg. 1987. Mathematical Methods. 2nd ed. Prentice-Hall Inc., Englewood Cliffs, NJ.

Richard, B., J. F. Le Page, P. Schuck, C. Andre, R. Jeantet, and G. Delaplace. 2013. Towards a better control of dairy powder rehydration processes. Int. Dairy J. 31:18-28.

Richard, B., M. Toubal, J. Le Page, G. Nassar, E. Radziszewski, B. Nongaillard, P. Debreyne, P. Schuck, R. Jeantet, and G. Delaplace. 2012. Ultrasound tests in a stirred vessel to evaluate the reconstitution ability of dairy powders. Innov. Food Sci. Emerg. Technol. $16: 233-242$.

Saggin, R., and J. N. Coupland. 2002. Ultrasonic monitoring of powder dissolution. J. Food Sci. 67:1473-1477.

Schuck, P., S. Mejean, A. Dolivet, C. Gaiani, S. Banon, J. Scher, and R. Jeantet. 2007. Water transfer during rehydration of micellar casein powders. Lait 87:425-432.

Sikand, V., P. S. Tong, S. Roy, L. E. Rodriguez-Saona, and B. A. Murray. 2011. Solubility of commercial milk protein concentrates and milk protein isolates. J. Dairy Sci. 94:6194-6202.

Yucel, U., and J. N. Coupland. 2011. Ultrasonic characterization of lactose crystallization in gelatin gels. J. Food Sci. 76:E48-E54. 